\title{
COMPUTATIONAL ENGINEERING OF PROTEIN L LIGANDS TO ACHIEVE AN OPTIMAL AFFINITY RESIN FOR PURIFICATION OF ANTIBODY FRAGMENTS
}

\section{SAMAN RAHMATI ${ }^{1}$, FATEMEH TORKASHVAND $* 1$, MASSOUD AMANLOU ${ }^{2}$, KOWSAR BAGHERZADEH $^{3,4}$, PEZHMAN FARD-ESFAHANI ${ }^{5}$, HOOMAN AGHAMIRZA MOGHIM ALIABADI ${ }^{1}$, BEHROUZ VAZIRI*1}

1- Biotechnology Research Center, Pasteur Institute of Iran, Tehran, Iran.

2- Department of Medicinal Chemistry, Faculty of Pharmacy, Tehran University of Medical Sciences, Tehran. Iran.

3- Eye Research Center, The Five Senses Institute Rassoul Akram Hospital, Iran University of Medical Sciences, Tehran, Iran;

4- Stem Cell and Regenerative Medicine Research Center, Iran University of Medical Sciences, Tehran, Iran.

5- Department of Biochemistry, Pasteur Institute of Iran, Tehran, Iran.

*Corresponding Authors:

Behrouz Vaziri

Behrouz-vaziri@pasteur.ac.ir

ORCID: 0000000202955922

Fatemeh Torkashvand

Fatemehtorkashvand4@gmail.com

ORCID: 0000000330661144

\section{Methods}

Hotspot Residue Determination and Prediction of Desired Mutations. The three-dimensional crystal structure of the B domain and Fab complex (PDB ID: 1HEZ) was retrieved from the Research Collaboratory for Structural Bioinformatics-Protein Data Bank (RCSB-PDB). Interacting residues of B domain-Fab complexes were predicted by LigPlot ${ }^{+} \mathrm{v} 1.4 .5^{1}$ and the hotspot residues in the B domain interfaces were predicted by computational alanine scanning ${ }^{2}$ and Support Vector Machine (SVM), and those reported in the literature were also considered. ${ }^{3,4}$ The B domain hotspot residues were predicted by Robetta ${ }^{5}$, DrugScore ${ }^{\text {PPI } 6}$, PPCheck ${ }^{7}$, KFC2 ${ }^{8}$, and PredHS webservers. ${ }^{9}$ Each interface residue was scored on the basis of the results provided by the web servers and residues that getting a score of at least 2 were considered as hotspot residues.

Osprey software version 2.2 Beta (Open-Source Protein Redesign for You) was used to predict the B domain mutants that would increase the binding affinity of B domain toward Fab. Non-hotspot residues in the first and the second interfaces of B domain were considered for mutation and were substituted with other 19 amino acids. ${ }^{10}$ The protein design algorithms MinDEE/A* in Osprey were used to determine the lowest binding energy and the most stabilizing mutations conformations beneath a steric threshold. Algorithm $\mathrm{K}^{*}$ was used to compute binding affinity of a protein-protein complex using structural ensembles to consider the most probable low-energy conformations and discard the majority of conformations that were rarely populated by the protein.

Molecular Docking Studies. The ClusPro ${ }^{11}$ and HADDOCK2.2 ${ }^{12}$ (High Ambiguity Driven protein-protein DOCKing) web servers were used to predict molecular interactions of the wild and mutated B domains as well as the engineered Proteins L (EPLs) with Fab. These web servers were also used to calculate an approximate binding energy as well as to obtain an appropriate mode of interactions to start MDS. The predicted putative interacting residues by LigPlot were dictated to the web servers (table S1). The best ranked models of complexes in the first and second interfaces were selected considering the type of interactions (mainly hydrogen bonds, hydrophobic and electrostatic interactions), the interacting residues, the binding energies and also the ClusPro and HADDOCK scores. The binding affinity (equilibrium dissociation constants: KD) of the obtained complexes were predicted using PRODIGY web server. ${ }^{13}$ The best ranked models were then applied as an appropriate mode of interactions to start Molecular Dynamic Simulations (MDS).

MDS. The models were solvated in a dodecahedral box of TIP3P water molecules with the minimum distance of $10 \AA$ between the protein surface and the box walls and the system net charge was neutralized by adding $\mathrm{Na}+$ or $\mathrm{Cl}^{-}$counter ions. The particle mesh Ewald method was used for the electrostatic interaction simulations. The Van der Waals cut-off was $14 \AA$ and periodic boundary conditions were assigned in all directions. The SHAKE method was used for the covalent bonds involving hydrogen. The whole system was then submitted to energy minimization employing steepest descent algorithm with tolerance of $1000 \mathrm{~kJ} / \mathrm{mol} / \mathrm{nm}$. After convergence, the system went through NVT ensemble (constant number of particles, volume and temperature) MDS for 20 ps. MDS was carried out employing NPT ensemble (constant number of particles, pressure and temperature) in a periodic boundary condition. Berendsen barostat and thermostat were applied to keep the pressure and temperature constant at 1 bar and $300 \mathrm{~K}$ with a coupling time of $\tau \mathrm{p}=0.5 \mathrm{ps}$, and $\tau \mathrm{T}=0.1 \mathrm{ps}$, respectively. The MDS were extended at constant pressure and temperature conditions.

MDS were carried out using GROMACS 2018.4 with AMBER force field (amber99sb-ildn) ${ }^{14}$ on the wild and mutated single B domains and Fab complexes as well as the EPLs and Fab complexes for the best ranked models from molecular docking as well as 
for the EPLs. ${ }^{15,16}$ Basic MD simulation trajectory analysis, including root mean square deviation (RMSD), root mean square fluctuation (RMSF), radius of gyration (Rg) and the secondary structure analysis (DSSP) were performed for the EPLs as well as docked complexes were evaluated by RMSD, RMSF, radius of gyration (Rg), the solvent accessible surface area (SASA) and hydrogen bonds analysis using GROMACS software.

Homology Modeling and Structure Evaluation of Proteins L. The amino acid sequence of B domain of Protein L (PDB ID: 1HEZ) was retrieved from the Research Collaboratory for Structural Bioinformatics Protein Data Bank (RCSB - PDB) which comprises of 61 amino acids ${ }^{3}$ and the amino acid sequence of linker was retrieved from strain 3316 of Peptostreptococcus magnus Protein L ( $\mathrm{Ppl}_{3316}$ strain) which comprises of 13 amino acids. ${ }^{17}$ The sequences were used to model the structure of four B domains. First, the 3D structure of three B domains was predicted by carrying out homology modeling using the GalaxyWEB web server ${ }^{18}$ and then the 3D structure of the four domains B was predicted by combining the B domain and three B domains using modeler v9.18 software. ${ }^{19}$ After homology modeling of the four domains B structure (M1), the predicted mutations in the first and second binding sites of the B domain were applied over each of the domains (as M2 and M3 for the first and the second binding site, respectively). The structure quality of the modeled proteins was assessed before and after energy minimization and after MDS using Rampage ${ }^{20}$, ProSA ${ }^{21}$, and Verify $3 \mathrm{D}^{22}$ web servers.

Graphical Representation. The Molecular Docking and MDS results were analyzed with the aid of VMD 1.9.3 software ${ }^{23}$,visualized using PyMol ${ }^{24}$ and Discovery Studio 4.1 Client. The graphs were all represented with the application of Microsoft Office Excel 2016.

Bacterial Strain, Plasmid, Reagents and Chemicals. The E. coli strain BL21 (DE3) and pET-26b (+) were used as expression host and expression vector, respectively. The E. coli strain BL21 (BL21 (Rosetta)) was provided by the Pasteur Institute of Iran (Tehran, Iran). pET-26b (+) and gene sequences were purchased from Biomatik company (Canada). The humanized IgG and chimeric mouse-human IgG were provided by AryoGen pharmed company (Iran). PCR reagents, and DNA ladders (1 kb) were purchased from CinnaClon (Iran) and Fermentas (UK), respectively. Protein molecular weight marker was purchased from Fermentas (UK). The membranes of Amicon ${ }^{\circledR}$ stirred cell were purchased from Millipore (Germany). All highly pure and analytical grade chemicals were purchased from GE Healthcare (UK), Merck (Germany) and Sigma (USA).

Cloning and Selection of Positive Clones. Amino acid sequences of the three engineered proteins were reverse translated into nucleotide sequence using GeneRunner software and codon optimized using Optimizer web server. ${ }^{25}$ The DNA sequences of the engineered Protein L genes were checked for restriction sites Nde1 and HindIII at 5' and 3' using GeneRunner software. Then, nucleotide sequences of the EPLs were chemically synthesized in pET-26b $(+)$ plasmid (Biomatik, Canada). The plasmids containing EPLs coding genes (pET-26b (+)-M1 / pET-26b (+)-M2 / pET-26b (+)-M3) were transformed into competent E. coli BL21 (Rosetta) by heat shock method according to Invitrogen protocols. The colonies obtained on LB agar plates containing kanamycin $(50 \mu \mathrm{g} / \mathrm{mL})$ were screened by colony PCR. The PCR product was evaluated by electrophoresis in $1 \%$ agarose gel and visualized by GelRed staining.

Protein Expression, Confirmation and purification. The positive colonies were cultured at $37^{\circ} \mathrm{C}$ while shaking in LB medium containing $50 \mathrm{mg} / 1$ kanamycin, then induced with $0.1 \mathrm{mM}$ IPTG (Sigma, USA), and further cultured at $37{ }^{\circ} \mathrm{C}$ for $4 \mathrm{~h}$. The cells harvested by centrifugation at $6000 \times \mathrm{g}$ for $20 \mathrm{~min}$. The expressions were analyzed on $12 \%$ SDS-polyacrylamide gels using Coomassie brilliant blue G250 (Merck, Germany) staining method. Western blotting was performed for identification of the expressed proteins using Ranibizumab as primary antibody (1/500 diluted, Genentech, USA) and HRP conjugated anti-kappa as secondary antibody (1/1000 diluted, Sigma, USA). The Protein L bands were revealed with DAB staining (Sigma, USA).

A chimeric mouse-human IgG was used as the ligand and CNBr-activated Sepharose 4B (GE Healthcare) as the matrix were used to produce an affinity chromatography resin. Briefly, matrix and ligand with the volume ratio $1: 1$ were incubated on a tube roller at room temperature $\left(25 \pm 1{ }^{\circ} \mathrm{C}\right)$ for 2 hours. Other reaction steps were performed according to the manufacturer's instructions (71-7086-00 AF, GE Healthcare).

For purification of EPLs, the cell pellets were resuspended in equilibration buffer (50 mM Tris buffer; $\mathrm{pH} 7.6,150 \mathrm{mM} \mathrm{NaCl}$, $0.05 \%$ Tween 20, $1 \mathrm{mM}$ PMSF (phenyl methyl-sulfonyl fluoride) and $1 \mathrm{mM}$ EDTA), sonicated on ice bath, centrifuged at $12000 \times \mathrm{g}$ for $30 \mathrm{~min}$, and the supernatant was filtered and loaded onto prepared IgG-Sepharose column. The target proteins were eluted using a buffer containing 0.5 M HAc; $\mathrm{pH}$ 3.4. The proteins purity was analyzed by SDS-PAGE, and isoelectric focusing electrophoresis. To confirm the protein identity of three purified proteins L, western blot analysis was performed using Ranibizumab as primary antibody and HRP conjugated anti-kappa as secondary antibody. The membrane was stained with the ECL Western Blotting reagent (GE Healthcare, UK).

$4.5 \mu \mathrm{g}$ of Protein L M1 was dissolved in rehydration buffer (8 M urea, 4\% CHAPS, $0.2 \%$ Biolyte, $50 \mathrm{mM}$ DTT and $0.001 \%$ bromo phenol blue) and IEF standard (pI 4.45-9.6, Bio-Rad, USA) was used for pI calibration, the samples individually were loaded onto the immobilized $\mathrm{pH}$ gradient (IPG) strips (7 cm, non-linear $\mathrm{pH} 3-10)$ and kept at room temperature for $16 \mathrm{~h}$. IEF was performed using three steps of increasing voltage from $250 \mathrm{~V}$ to $14 \mathrm{kV}$. Finally, IPG strips were stained by Bio-Rad special dye (Bio-Rad, country) for $30 \mathrm{~min}$ and destained by $40 \%$ methanol, $10 \%$ glacial acetic acid solution.

Mass spectrometry analysis was performed to determine the M3 molecular weight using MALDI TOF/TOF method.

Surface Plasmon Resonance (SPR) Analysis. The binding affinity of EPLs to a chimeric mAb and a humanized Fab was determined by SPR analysis. SPR experiments were accomplished by Biacore X100 (GE Healthcare, Sweden) on CM5 (CM5 carboxymethyl dextran) sensor chip (GE Healthcare). For affinity analysis of EPLs ligands to a chimeric monoclonal antibody, an anti-fc antibody (from human antibody capture kit, GE Healthcare) was amine coupled in the active and reference flow cell of a CM5 chip according to the manufacturer's instructions. A chimeric mouse-human IgG was used as a ligand and injected at 0.5 $\mathrm{ug} / \mathrm{ml}$ at flow rate of $5 \mu \mathrm{l} / \mathrm{min}$ for $180 \mathrm{~s}$ in active flow cell only, with a surface density of about 600 resonance units (RU). Multi 
cycle kinetics procedure was applied. A range of three EPLs concentrations (115.7, 38.5, 12.8, 4.2, and 1.4 nM) was injected into flow cells, with a contact and dissociation time of 120 and 500 seconds, respectively. After each cycle, the chip was regenerated with regeneration buffer (glycine- $\mathrm{HCl}$ at $\mathrm{pH} 2.5$ ) to eliminate all the binding proteins. Responses from an empty flow cell and from buffer injections were subtracted from recorded values.

For affinity analysis of EPLs ligands to a fab fragment, a Fab binder (from fab capture kit, GE Healthcare) was amine coupled in the active and reference flow cell of a CM5 chip, according to the manufacturer's instructions. A humanized fab fragment was used as a ligand and injected at $5 \mathrm{ug} / \mathrm{ml}$ at flow rate of $5 \mu \mathrm{l} / \mathrm{min}$ for $180 \mathrm{~s}$ in active flow cell only, with a surface density of about 900 resonance units (RU). Single cycle kinetics procedure was applied. A range of three EPLs concentrations $(265,132.5,66.25,33.1$, and $16.6 \mathrm{nM}$ ) was injected into flow cells, with a contact and dissociation time of 120 and 500 seconds, respectively. The chip was regenerated with regeneration buffer (glycine- $\mathrm{HCl}$ at $\mathrm{pH} 2.5$ ). Responses from an empty flow cell and from buffer injections were subtracted from recorded values. Kinetic analyses were performed by Biacore X100 evaluation software version 2 and ka (association rate constant), $\mathrm{kd}$ (dissociation rate constant) and $\mathrm{KD}$ (equilibrium dissociation constant) parameters were finally determined.

Coupling EPLs to CNBr-activated Sepharose 4B. The resin was activated in $1 \mathrm{mM} \mathrm{HCl}$ for $5 \mathrm{~min}$, followed by centrifugation at $300 \mathrm{~g}$ for $2 \mathrm{~min}$, the supernatant was discarded and activation step was repeated at least 3 times. Then resin (corresponding to 1 $\mathrm{mL}$ settled resin) was suspended in coupling buffer $(150 \mathrm{mM} \mathrm{NaHCO} 3,500 \mathrm{mM} \mathrm{NaCl} ; \mathrm{pH} 8.3)$ followed by centrifugation at 300 $\mathrm{g}$ for $2 \mathrm{~min}$. $2 \mathrm{ml}$ of Protein L ligand with the concentration of $10 \mathrm{mg} / \mathrm{ml}$ which buffer exchanged against coupling buffer (150 mM $\mathrm{NaHCO} 3,500 \mathrm{mM} \mathrm{NaCl}$; pH 8.3) by ultrafiltration using Amicon Ultracentrifugal filter units (10000 MWCO; $15 \mathrm{ml}$; Millipore, Germany) was added into the activated resin and the coupling proceeded on a tube roller at room temperature $\left(25 \pm 1^{\circ} \mathrm{C}\right)$ for 2 hours. After coupling step, resin- ligand coupling mixture was centrifuged at $300 \mathrm{~g}$ for $2 \mathrm{~min}$ and the supernatant was collected for protein quantification by Bradford assay. Coupling buffer was added to the coupled resin, mixed gently and centrifuged at $300 \mathrm{~g}$ for $2 \mathrm{~min}$. washing was repeated at least 3 times. Blocking of residual active groups was performed by addition of blocking buffer: $1 \mathrm{M}$ Ethanolamine, $\mathrm{pH} 8$ and incubated on a tube roller at room temperature for 2 hours. After the blocking step, the resin was washed three cycles with alternating two buffer: the first wash buffer, $0.1 \mathrm{M}$ sodium acetate, $0.5 \mathrm{M} \mathrm{NaCl} ; \mathrm{pH} 4.0$ and the second wash buffer, $0.1 \mathrm{M}$ Tris- $\mathrm{HCl}, 0.5 \mathrm{M} \mathrm{NaCl} ; \mathrm{pH}$ 8.0. Finally, coupled resin was stored in $20 \%$ ethanol at $4{ }^{\circ} \mathrm{C}$.

Coupling EPLs to Epoxy-activated Sepharose 6B. The resin was washed and swelled in sterile water, followed by centrifugation at $300 \mathrm{~g}$ for $2 \mathrm{~min}$, the supernatant was discarded and activation step was repeated at least 3 times. Then resin (corresponding to 1 $\mathrm{mL}$ settled resin) was suspended in coupling buffer $(0.1 \mathrm{M} \mathrm{Na} 2 \mathrm{CO} 3,0.1 \mathrm{M} \mathrm{NaHCO} 3,150 \mathrm{mM} \mathrm{NaCl}$; pH 9-12) followed by centrifugation at $300 \mathrm{~g}$ for $2 \mathrm{~min} .2 \mathrm{ml}$ of Protein L ligand with the concentration of $10-30 \mathrm{mg} / \mathrm{ml}$ which buffer exchanged against coupling buffer by ultrafiltration using Amicon Ultracentrifugal filter units ( $10000 \mathrm{MWCO} ; 15 \mathrm{ml}$; Millipore, Germany) was added into the activated resin and the coupling proceeded on a tube roller at $25-35{ }^{\circ} \mathrm{C}$ for 16 hours. After coupling step, resin- ligand coupling mixture was centrifuged at $300 \mathrm{~g}$ for $2 \mathrm{~min}$ and the supernatant was collected for protein quantification by Bradford assay. Coupling buffer was added to the coupled resin, mixed gently and centrifuged at $300 \mathrm{~g}$ for $2 \mathrm{~min}$. washing was repeated at least 3 times. Blocking of residual active groups was performed by addition of blocking buffer: $1 \mathrm{M}$ Ethanolamine, $\mathrm{pH} 8$ and incubated on a tube roller at $30^{\circ} \mathrm{C}$ for 4 hours. After the blocking step, the resin was washed three cycles with alternating two buffer: the first wash buffer, $0.1 \mathrm{M}$ sodium acetate, $0.5 \mathrm{M} \mathrm{NaCl} ; \mathrm{pH} 4.0$ and the second wash buffer, $0.1 \mathrm{M}$ Tris- $\mathrm{HCl}, 0.5 \mathrm{M} \mathrm{NaCl}$; $\mathrm{pH} \mathrm{8.0.} \mathrm{Finally,}$ coupled resin was stored in $20 \%$ ethanol at $4{ }^{\circ} \mathrm{C}$.

Fab Preparation. A humanized IgG $(20 \mathrm{mg} / \mathrm{ml})$ was digested using papain. Antibody was buffer exchanged against PBS buffer pH 7.4 by ultrafiltration using Amicon Ultracentrifugal filter units (10000 MWCO; 15ml; Millipore, Germany). Papain (Sigma, USA) activation was performed by incubation in $10 \mathrm{mM}$ PBS, $20 \mathrm{mM}$ EDTA, $10 \mathrm{mM}$ Cystein- $\mathrm{HCl}$; $\mathrm{pH} 7.4$ for $10 \mathrm{~min}$ at $37^{\circ} \mathrm{C}$. Antibody and papain solution were incubated in a rotator mixer at a papain: IgG ratio of 1:20 (w/w) for 4.5 hours at $37{ }^{\circ} \mathrm{C}$. The reaction was stopped with the addition of a protease inhibitor cocktail (Roche, Germany). ${ }^{26}$ Fab fragments were purified by two affinity chromatography steps by MabSelect $\mathrm{SuRe}^{\mathrm{TM}}$ (GE Healthcare, Sweden) and Capto ${ }^{\mathrm{TM}} \mathrm{L}$ (GE Healthcare, Sweden) columns. The purification steps were performed based on the manufactures instructions. Fab fragments were removed from the column in flow through step and untreated antibodies and Fc fragments were captured to MabSelect SuRe ${ }^{\mathrm{TM}}$ resin. For more purity of Fab fragments, solution containing Fab was loaded on $1 \mathrm{~m}$ Capto $^{\mathrm{TM}} \mathrm{L}$ resin.

Determination of DBC. The engineered Protein L resins were packed into $1 \mathrm{ml}$ biocomma ${ }^{\circledR}$ empty FPLC columns (Biocomma). The DBC of the resins was measured at $10 \%$ breakthrough for an enzymatically prepared Fab. The EPLs and Capto ${ }^{\mathrm{TM}} \mathrm{L}$ resins were equilibrated with equilibration buffer containing $20 \mathrm{mM}$ Sodium phosphate, $150 \mathrm{mM} \mathrm{NaCl} ; \mathrm{pH} 7.2$. The Fab in equilibration buffer $(1.5 \mathrm{mg} / \mathrm{ml})$ was loaded until breakthrough curve was observed. The columns were then washed with the equilibration buffer and eluted with elution buffer containing $100 \mathrm{mM}$ Glycine- $\mathrm{HCl} ; \mathrm{pH} 3.5$, the flow rate was $0.6 \mathrm{~mL} \mathrm{~min}^{-1}$. DBC of each resin was determined at $10 \%$ breakthrough and calculated according to the formula: $\mathrm{DBC}(\mathrm{mg} \cdot \mathrm{ml})-1=\mathrm{V} 10 \% \times \mathrm{Cp} / \mathrm{Vcol}$

$$
\text { / }
$$

Which $\mathrm{V}_{10 \%}(\mathrm{ml})$ is the volume loaded to reach $10 \%$ breakthrough, $\mathrm{C}_{\mathrm{p}}(\mathrm{mg} / \mathrm{ml})$ is the concentration of the protein, and $\mathrm{V}_{\mathrm{col}}(\mathrm{ml})$ is the geometric total volume of the column.

Determination of Protein Recovery. The application test was made by mixing $30 \%$ of the Fab and $70 \%$ proteins in $E$. coli lysate. The columns were loaded with the mixture of the sample and HCPs and the flow rate was adjusted as $0.6 \mathrm{~mL} \mathrm{~min}^{-1}$ at all steps. The columns were equilibrated and then washed with $20 \mathrm{mM}$ sodium phosphate, $150 \mathrm{mM} \mathrm{NaCl} ; \mathrm{pH} 7.2$ to remove unbound proteins. Then columns were eluted with $100 \mathrm{mM}$ Glycine- $\mathrm{HCl}$; $\mathrm{pH} 3.5$. The concentrations of elution fractions were determined using 
NanoDrop ${ }^{\circledR}$ ND-1000 UV-Vis Spectrophotometer at a wavelength of $280 \mathrm{~nm}$. The targets purity was analyzed using SDS-PAGE and size exclusion chromatography.

Size Exclusion Chromatography (SEC). The SEC chromatography was performed on a liquid chromatograph (KNAUER AZURA Analytical HPLC system, Germany). The elution fraction samples containing Fabs which recovered by the EPLs and Capto $^{\mathrm{TM}} \mathrm{L}$ resins were buffer exchanged against phosphate buffer, $\mathrm{pH} 7.2$ by ultrafiltration using Amicon Ultracentrifugal filter units (10000 MWCO; $15 \mathrm{ml}$; Millipore, country). $80 \mu \mathrm{g}$ of each of purified and standard proteins applied to a G2000 SEC column $(7.8 \times 300 \mathrm{~mm})$ (Tosoh Bioscience, Germany) with $20 \mathrm{mM}$ sodium phosphate, $150 \mathrm{mM} \mathrm{NaCl}$; $\mathrm{pH} 7.2$ as a mobile phase solution with a flow rate of $0.5 \mathrm{~mL} \mathrm{~min}^{-1}$. The elution profiles were monitored by UV absorbance at $280 \mathrm{~nm}$. The purity of Fabs recovered by the EPLs and Capto ${ }^{\mathrm{TM}} \mathrm{L}$ resins was determined by measuring the peak area of SEC column elution.

\section{RESULTS}

Molecular Docking and MDS Studies of the B domains and Fab. The Ligplot analysis exhibited that the number of hydrogen bonds (H-bond) between the mutated B domain and Fab (10 H-bonds) was more than the hydrogen bonds number between the wild $\mathrm{B}$ domain and Fab (8 H-bonds) in the first binding site. Also, in the second binding site, the number of hydrogen bonds in the wild B domain and Fab complex were $11 \mathrm{H}$-bonds, while these bonds became 14 after mutation (Figure $\mathrm{S} 1$ ).

The reduction in SASA values indicates a decrease in solvent accessible area and an increase in the binding affinity between the two proteins. According to Figure S2E, the average SASA values in the mutated B domain-Fab complex $\left(110 \mathrm{~nm}^{2}\right) \mathrm{was}_{\text {lower than }}$ the wild type B domain-Fab complex $\left(111 \mathrm{~nm}^{2}\right)$ in the first binding site as well as in the second binding site, the average SASA values in the mutated B domain-Fab complex $\left(109 \mathrm{~nm}^{2}\right)$ was lower than of the wild type B domain-Fab complex $\left(116 \mathrm{~nm}^{2}\right)($ Figure S2E).

The hydrogen bond (H-bond) analysis was performed to calculate the average number of H-bonds in regions of Protein-Protein interaction in the four complexes. The criterion for hydrogen bonding was set at $3.5 \AA$ distance between electron donor atom and hydrogen of electron acceptor atom. The number of hydrogen bonds (H-bond) in the mutated B domain-Fab complex in the first binding site with the average number of $23 \mathrm{H}$-bonds was more than that for the wild type $\mathrm{B}$ domain-Fab complex with the average number of $21 \mathrm{H}$-bonds. Also, the number of hydrogen bonds in the mutated B domain-Fab complex in the second interface, with the average number of $18 \mathrm{H}$-bonds, was more in comparison with the wild B domain-Fab complex with $17 \mathrm{H}$-bond interactions.

Homology Modeling, Structural Validation and MDS Studies of the EPLs. The predicted mutations in the first binding site of the B domain by Osprey were applied in four B domain as M2 (including; Lys5Arg, Ilu15Leu, Ala18Thr, Lys21Arg, Leu37Trp, Lys77Arg, Ilu87Leu, Ala90Thr, Lys93Arg, Leu109Trp, Lys151Arg, Ilu161Leu, Ala164Thr, Lys167Arg, Leu183Trp, Lys225Arg, Ilu235Leu, Ala238Thr, Lys241Arg and Leu257Trp). Also, the predicted mutations for the second binding site of B domain were subjected in four B domain as M3, (containing; Phe24Tyr, Thr28Met, Ala29Arg, Thr46Trp, Gly52Trp, Phe96Tyr, Thr100Met, Ala101Arg, Thr118Trp, Gly124Trp, Phe170Tyr, Thr174Met, Ala175Arg, Thr192Trp, Gly198Trp, Phe244Tyr, Thr248Met, Ala249Arg, Thr266Trp, Gly272Trp). The 3D structure of the four B domains without mutation as M1 were modeled using the GalaxyWEB web server and the modeller v9.18 software. The three modeled Proteins L as shown in Figure S3.

The psi and phi distribution of the Ramachandran plots for the structures showed that the majority of the amino acid residues were presented in the favorable region. The ProSA plots indicated that the overall the structures quality was within the range of scores typically found for native proteins of similar size. The Verify-3D profile scores for the structures demonstrated that the majority of the residues had an average 3D-1D score of $\geq 0.2$.

Molecular Docking and MDs Studies of the EPLs and Fab. The Ligplot analysis exhibited that the number of hydrogen bonds between M2 and Fab with $19 \mathrm{H}$-bonds was more than $15 \mathrm{H}$-bonds between M1 and Fab in the first binding site as well as, M3-Fab complex (13 bonds) had more H-bonds compared to M1-Fab complex (11 bonds) in the second binding site (Figure S6).

The average SASA values in M2-Fab complex $\left(140 \mathrm{~nm}^{2}\right)$ was lower than Model-1 -Fab complex $\left(148 \mathrm{~nm}^{2}\right)$ in the first binding site, as well as the average SASA values in Model-3- Fab complex $\left(141 \mathrm{~nm}^{2}\right)$ was lower than M1-Fab complex $\left(145 \mathrm{~nm}^{2}\right)$ in the second binding site (Figure S7E).

The average number of hydrogen bonds in the M2-Fab complex in the first binding site with the average number of $25 \mathrm{H}-\mathrm{bonds}$ was more than $22 \mathrm{H}$-bonds in the M1-Fab complex in this interface, as well as the average number of hydrogen bonds in the M3Fab complex in the second binding site with the average number of $20 \mathrm{H}$-bonds was more in comparison to $18 \mathrm{H}$-bonds in the M1Fab complex in this site.

Recombinant Producing of EPLs. The EPLs expression in lysate were confirmed by western blotting (Figure S9). Isoelectric focusing (IEF) analysis was performed to identify the pI of two bands of purified EPLs from IgG-Sepharose column. Purified M1 was selected as the sample. IEF analysis determined two bands of M1 have pI around 4.45 as shown in Figure S10. The pI of M1 was predicted 4.4 by ExPasy web server, which was matched well with the experimentally determined pI. This method confirmed both bands of purified M1 are Protein L.

The SDS-PAGE analysis of purified EPLs (Figure S7B-S7D) showed that these proteins appear in two bands and the tests including western blotting, isoelectric focusing and mass spectrometry were conducted to identify two bands. Western blotting confirmed both bands of purified EPLs are Protein L (Figure S7E), also isoelectric focusing determined both bands of purified M1 have one $\mathrm{pI}$ which was matched well with the M1 pI evaluated by ExPasy web server (Figure S9). Moreover, mass spectrometry analysis (MALDI TOF/TOF) for purified M3 indicated that there was only one main peak in area of $30 \mathrm{KDa}$ which was matched with the M3 molecular weight evaluated by ExPasy web server (Figure S11). Furthermore, Akerström B. et al., showed that the purified native Protein L from cell wall of Peptostreptococcus magnus appears in two bands in an agarose gel electrophoresi s 27 . 
Table S1- A list of putative interacting residues in the protein-protein interface for B domain and Fab proteins using LigPlot software

\begin{tabular}{|c|c|c|c|}
\hline $\begin{array}{l}\text { The first interface of } \mathrm{B} \\
\text { domain }\end{array}$ & $\begin{array}{c}\text { Fab fragment interacting } \\
\text { with the first interface of } \\
\text { B domain }\end{array}$ & $\begin{array}{l}\text { The second interface of } \mathrm{B} \\
\text { domain }\end{array}$ & $\begin{array}{c}\text { Fab fragment interacting with } \\
\text { the second interface of } \mathrm{B} \\
\text { domain }\end{array}$ \\
\hline $\begin{array}{l}\text { Lys824, Leu834, Gln835, } \\
\text { Tht836, Thr837, Glu838, } \\
\text { Phe839, Arg840, Glu849, } \\
\text { Arg852, Tyr853, Trp856 }\end{array}$ & $\begin{array}{l}\text { Thr5, Pro8, Ser9, Ser10, } \\
\text { Leu11, Ser12, Ala13, } \\
\text { Thr20, Thr22, Arg24, } \\
\text { Lys107, Glu143 }\end{array}$ & $\begin{array}{l}\text { Phe843, Glu844, Thr847, } \\
\text { Ala848, Tyr851, Arg852, } \\
\text { Asp855, Tyr864, Thr865, } \\
\text { Ala866, Asp867, Leu868, } \\
\text { Glu869, Gly87 }\end{array}$ & $\begin{array}{c}\text { Ser7, Pro8, Ser10, Leu11, } \\
\text { Ser12, Ala13, Asp17, Arg18, } \\
\text { Thr20, Arg24, Ser65, Thr72, } \\
\text { Thr74, Lys107 }\end{array}$ \\
\hline
\end{tabular}

Table S2- Hotspot (HS) residues analysis of the B domain in the first B domain-Fab interface.

\begin{tabular}{|c|c|c|c|c|c|c|c|c|}
\hline $\begin{array}{c}\text { The first interface of } \\
\text { B domain }\end{array}$ & $\begin{array}{c}\text { Experimental } \\
\text { Data }\end{array}$ & $\begin{array}{c}\text { Drug } \\
\text { ScorePPI }\end{array}$ & Robetta & PPCheck & PredHS & KFC2 & Score & Results \\
\hline Glu849 & & & & HS & HS & HS & 3 & Hotspot \\
\hline Arg852 & & & & HS & HS & & 2 & Hotspot \\
\hline Gln835 & & & HS & HS & HS & & 3 & Hotspot \\
\hline Thr836 & HS & & & HS & HS & & 3 & Hotspot \\
\hline Leu856 & & & & HS & & 1 & Non hotspot \\
\hline Tyr853 & HS & HS & HS & HS & HS & & 5 & Hotspot \\
\hline Phe839 & & & HS & HS & & & 2 & Hotspot \\
\hline Lys840 & & & HS & & & 1 & Non hotspot \\
\hline Glu838 & & & & HS & HS & HS & 3 & Hotspot \\
\hline Ala837 & & & & & & & 0 & Non hotspot \\
\hline Lys824 & & & & HS & & & 1 & Non hotspot \\
\hline Ilu834 & & & & HS & & & 1 & Non hotspot \\
\hline
\end{tabular}


Table S3- Hotspot (HS) residues analysis of the B domain in the second B domain-Fab interface

\begin{tabular}{|c|c|c|c|c|c|c|c|c|}
\hline $\begin{array}{l}\text { The second } \\
\text { interface of B } \\
\text { domain }\end{array}$ & $\begin{array}{c}\text { Experimental } \\
\text { data }\end{array}$ & $\begin{array}{c}\text { Drug } \\
\text { ScorePPI }\end{array}$ & Robetta & PCheck & PredHS & $\mathrm{KFC} 2$ & Score & Results \\
\hline Thr865 & & & & HS & & & 1 & Non hotspot \\
\hline Arg852 & & & & & HS & HS & 2 & Hotspot \\
\hline Asp855 & HS & & & HS & HS & HS & 4 & Hotspot \\
\hline Tyr864 & HS & & & HS & HS & & 3 & Hotspot \\
\hline Glu844 & & & HS & HS & HS & HS & 4 & Hotspot \\
\hline Tyr851 & & HS & HS & HS & HS & & 4 & Hotspot \\
\hline Thr847 & & & & & HS & & 1 & Non hotspot \\
\hline Phe843 & & & & & HS & & 1 & Non hotspot \\
\hline Gly871 & & & & & & & 0 & Non hotspot \\
\hline Leu868 & & HS & HS & $\mathrm{HS}$ & HS & & 4 & Hotspot \\
\hline Ala866 & HS & & & & & HS & 2 & Hotspot \\
\hline Asp867 & & & & HS & HS & $\mathrm{HS}$ & 3 & Hotspot \\
\hline Glu869 & & & & HS & & HS & 2 & Hotspot \\
\hline Ala848 & & & & & HS & & 1 & Non hotspot \\
\hline Gly872 & & & & & & & 0 & Non hotspot \\
\hline
\end{tabular}



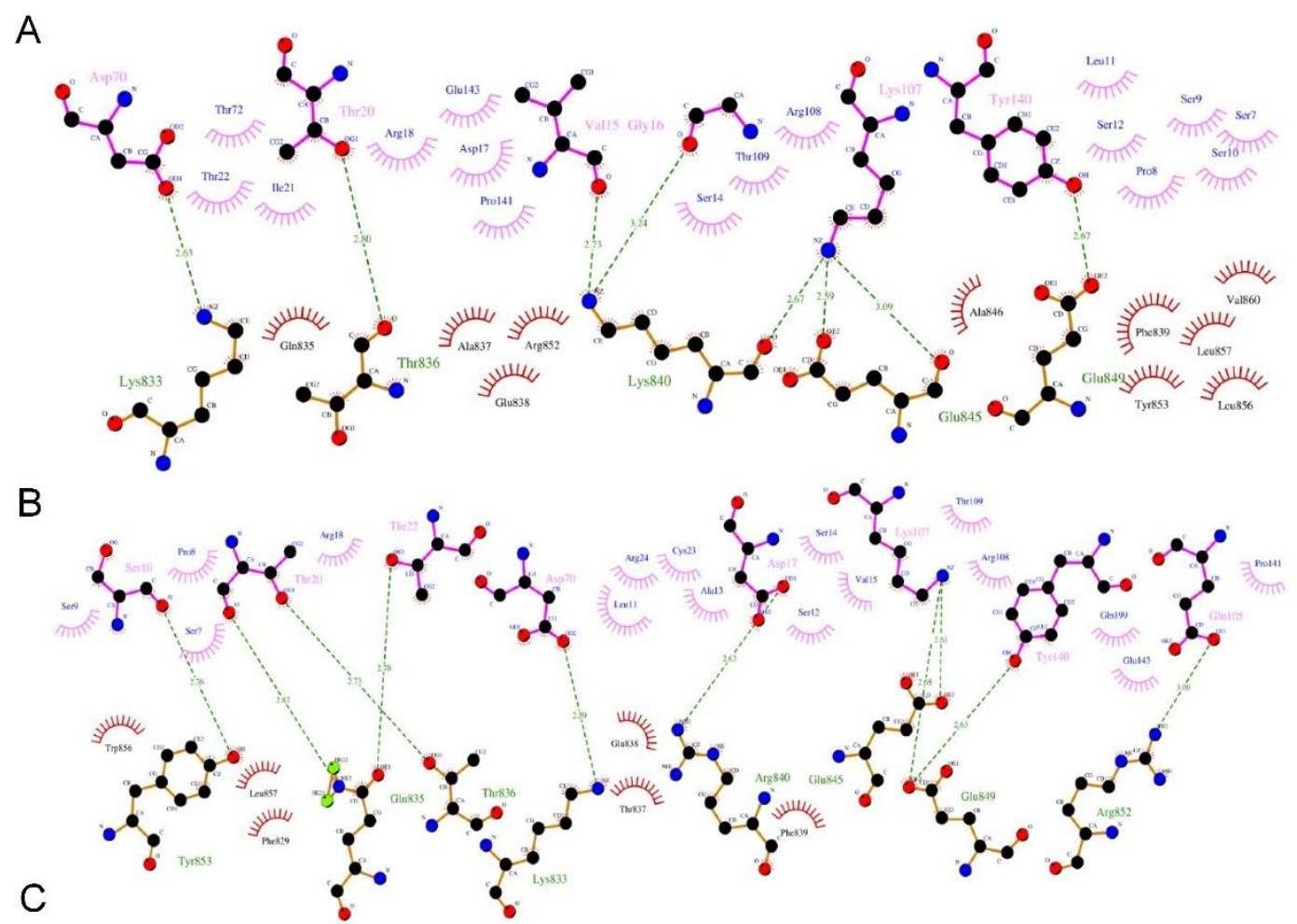

C
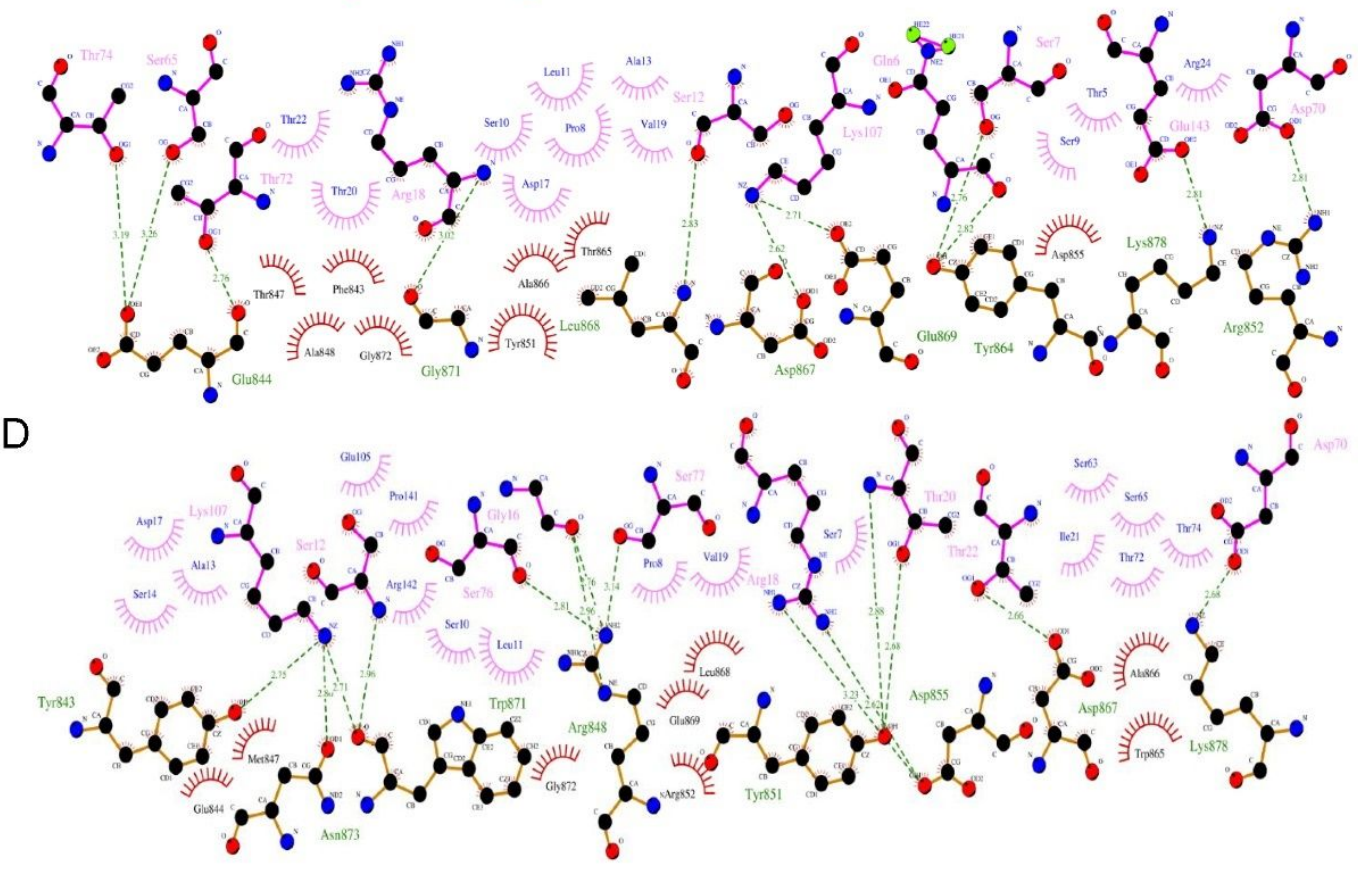

Figure S1. LigPlot analysis to determine the molecular interactions of the wild and mutated B domains with Fab fragment. Interactions of the wild B domain-Fab fragment (A) and the mutated B domain-Fab fragment (B) in the first binding site and interactions of the wild B domain-Fab fragment (C) and the mutated B domain-Fab fragment (D) in the second binding site were displayed using LigPlot. Residues of the wild and mutated B domains (red), Fab fragment (pink) and hydrogen bonds (green bonds) were indicated. 

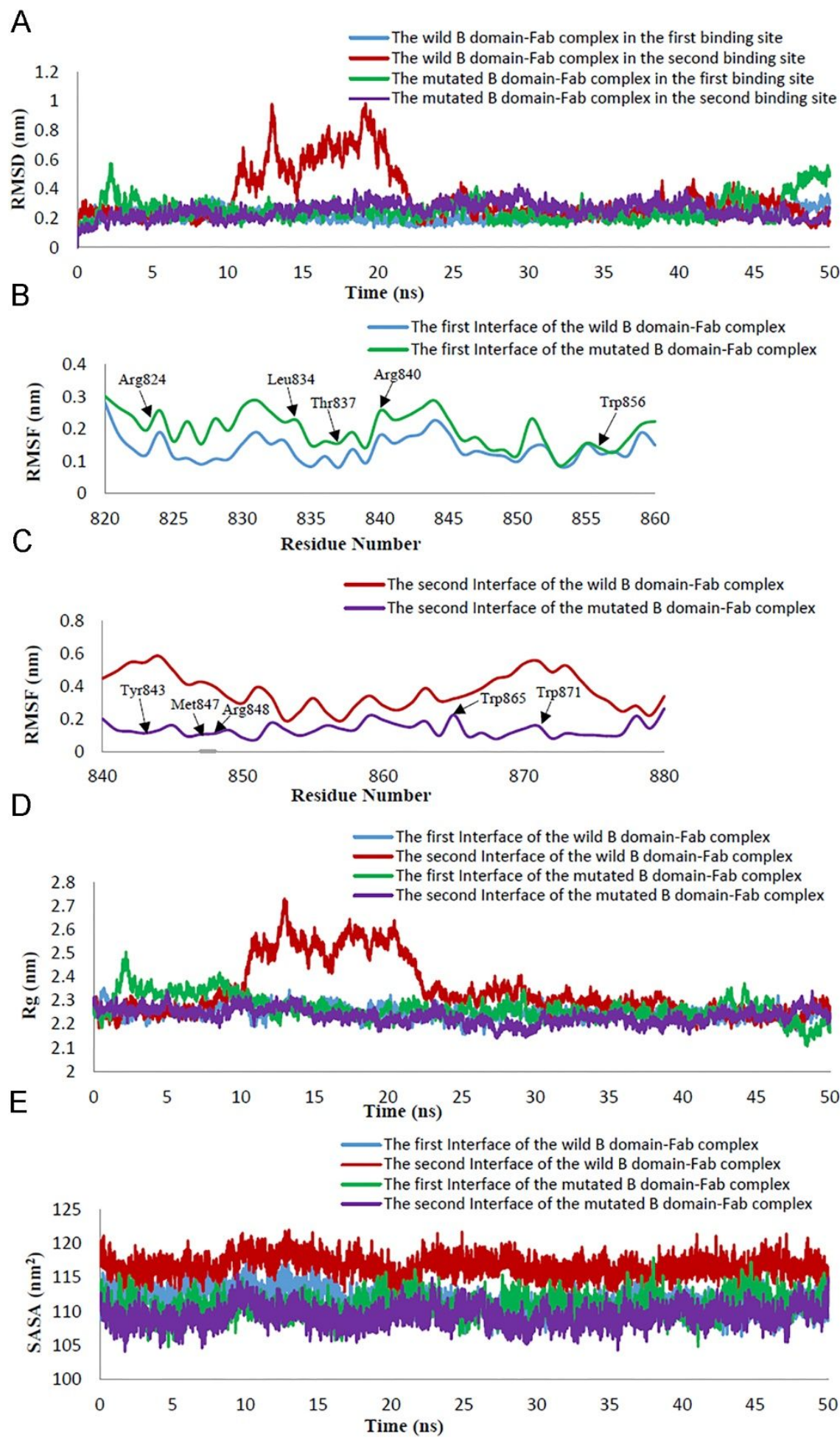

Figure S2. Molecular dynamics simulation of the wild and mutated B domains-Fab complexes during 50ns. (A) The RMSD plot, (b, c) The RMSF plot, (B) mutations of Arg824, Leu834, Thr837, Arg840 and Trp856 in the first binding site of B domain (residues 820-860) and (C) mutations of Tyr843, Met847, Arg848, Trp865, Trp871 in the second binding site of B domain (residues 840880) were presented in plots, (D) The radius of gyration plot, (E) SASA plot were shown. The wild B domain- Fab complex in the first binding site (blue), the wild B domain-Fab complex in the second binding site (red), the mutated B domain- Fab complex in 
the first binding site (green), the mutated B domain- Fab complex in the second binding site (purple) has represented complexes during MD simulation.

Table S4- Comparison of protein structure validation scores before and after energy minimization of target protein from RAMPAGE, ProSA and Verify 3D web servers

\begin{tabular}{|c|c|c|c|c|c|c|c|c|c|c|c|c|}
\hline Web servers & $\begin{array}{c}\text { M1 } \\
\text { (B EM) }\end{array}$ & $\begin{array}{c}\text { M1 } \\
\text { (A EM) }\end{array}$ & $\begin{array}{c}\text { M1 (A } \\
\text { MD } \\
50 \mathrm{~ns})\end{array}$ & $\begin{array}{c}\text { M1 (A } \\
\text { MD } \\
100 \mathrm{~ns})\end{array}$ & $\begin{array}{c}\text { M2 (B } \\
\text { EM) }\end{array}$ & $\begin{array}{c}\text { M2 } \\
\text { (A EM) }\end{array}$ & $\begin{array}{c}\text { M2 (A } \\
\text { MD } \\
50 \mathrm{~ns})\end{array}$ & $\begin{array}{c}\text { M2 (A } \\
\text { MD } \\
100 \mathrm{~ns})\end{array}$ & $\begin{array}{c}\text { M3 (B } \\
\text { EM) }\end{array}$ & $\begin{array}{c}\text { M3 (A } \\
\text { EM) }\end{array}$ & $\begin{array}{c}\text { M3 (A } \\
\text { MD } \\
50 \mathrm{~ns})\end{array}$ & $\begin{array}{c}\text { M3 (A } \\
\text { MD } \\
100 \mathrm{~ns})\end{array}$ \\
\hline $\begin{array}{c}\text { RAMPAGE } \\
\text { Favored } \\
\text { region (\%) }\end{array}$ & 97.9 & 96.0 & 94.0 & 94.2 & 98.9 & 95.7 & 97.1 & 95.7 & 98.9 & 96.8 & 95.7 & 95.7 \\
\hline $\begin{array}{c}\text { RAMPAGE } \\
\text { Allowed } \\
\text { region (\%) }\end{array}$ & 0.7 & 2.2 & 3.7 & 4.7 & 0.7 & 4.3 & 2.9 & 4.3 & 0.7 & 3.2 & 4.3 & 4.3 \\
\hline $\begin{array}{c}\text { RAMPAGE } \\
\text { Outlier region } \\
(\%)\end{array}$ & 1.4 & 1.8 & 2.2 & 1.1 & 0.4 & 0.0 & 0.0 & 0.0 & 0.4 & 0.0 & 0.0 & 0.0 \\
\hline $\begin{array}{c}\text { ProSA (Z- } \\
\text { score) }\end{array}$ & -5.39 & -5.41 & -4.14 & -5.75 & -5.13 & -5.84 & -6.15 & -5.45 & -4.71 & -5.61 & -5.45 & -5.56 \\
\hline \begin{tabular}{c} 
Verify 3D (\%) \\
\hline
\end{tabular} & 96.44 & 82.21 & 80.68 & 92.53 & 98.22 & 84.70 & 92.53 & 93.59 & 98.22 & 89.32 & 91.10 & 84.34 \\
\hline
\end{tabular}

The modeled protein structure is considered to be a good model when: 1) Value of Z-score (in ProSA) is between -15 and 10; 2) favored region $>98 \%$, allowed region $<2.0 \%$, outlier $0 \%$; 3) number of residues passing in Verify $3 \mathrm{D}$ should be $>80 \%$. EM: Energy Minimization. The Protein L of Model-1; M1, The Protein L of Model-2; M2, The Protein L of Model-3; M3, Before energy minimization; B EM, After energy minimization; A EM, After molecular dynamics; A MD. 

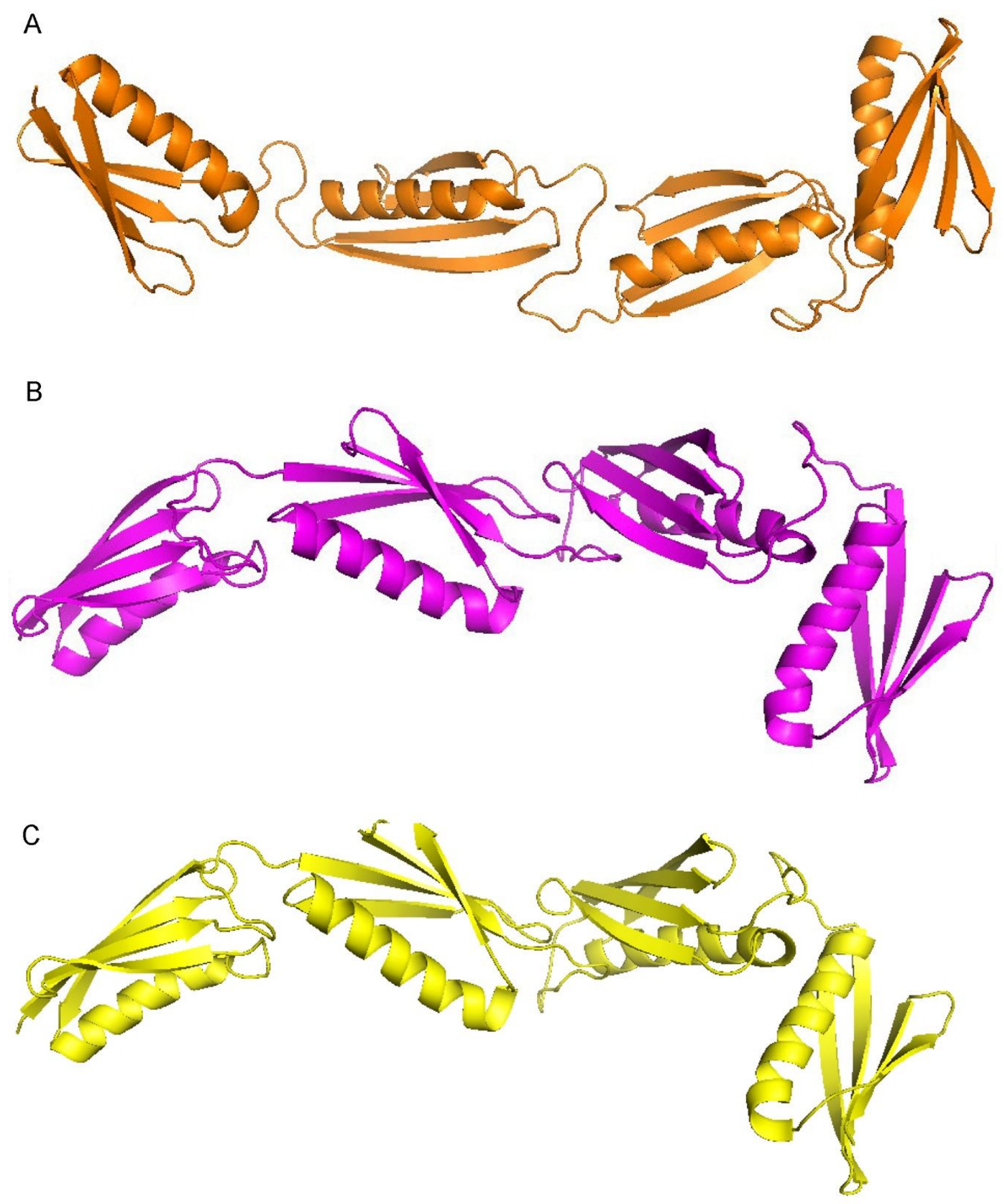

Figure S3- The structures of modeled Proteins L using the GalaxyWEB web server and the modeller v9.18 software. M1 (A), M2 (B) and M3 (C) demonstrated the structures of modeled Proteins L. 

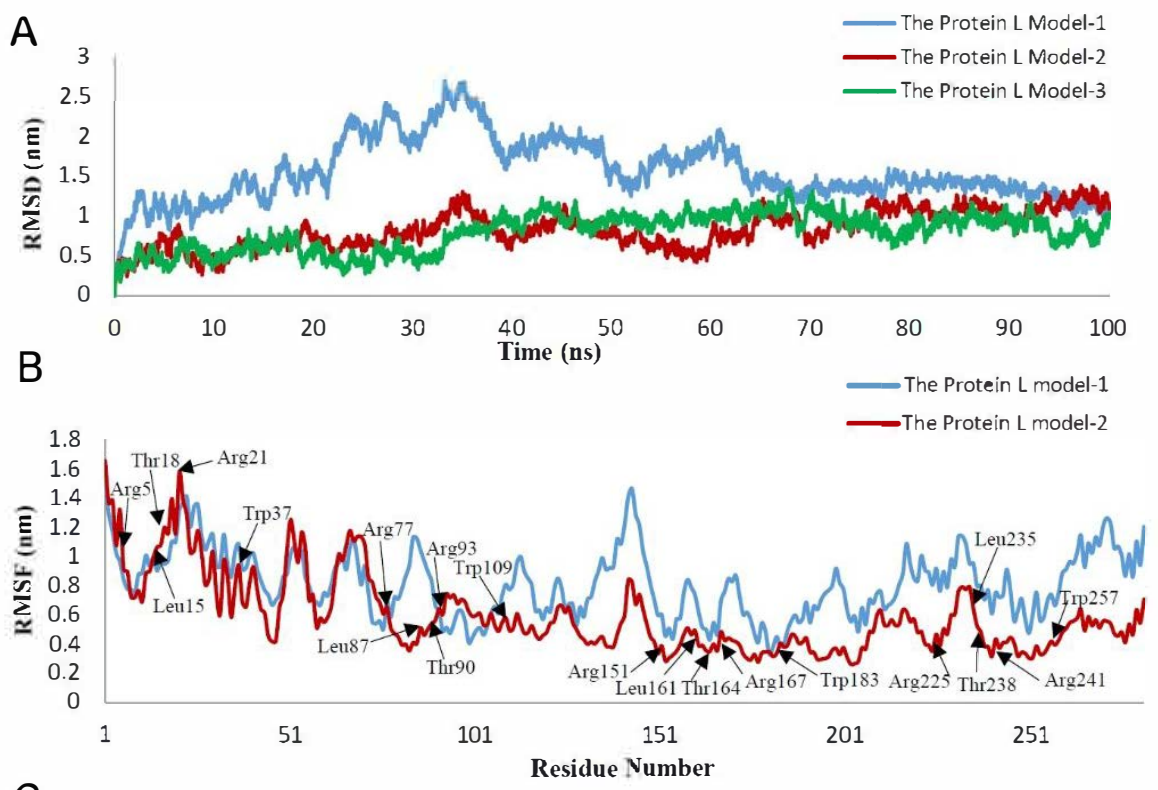

C
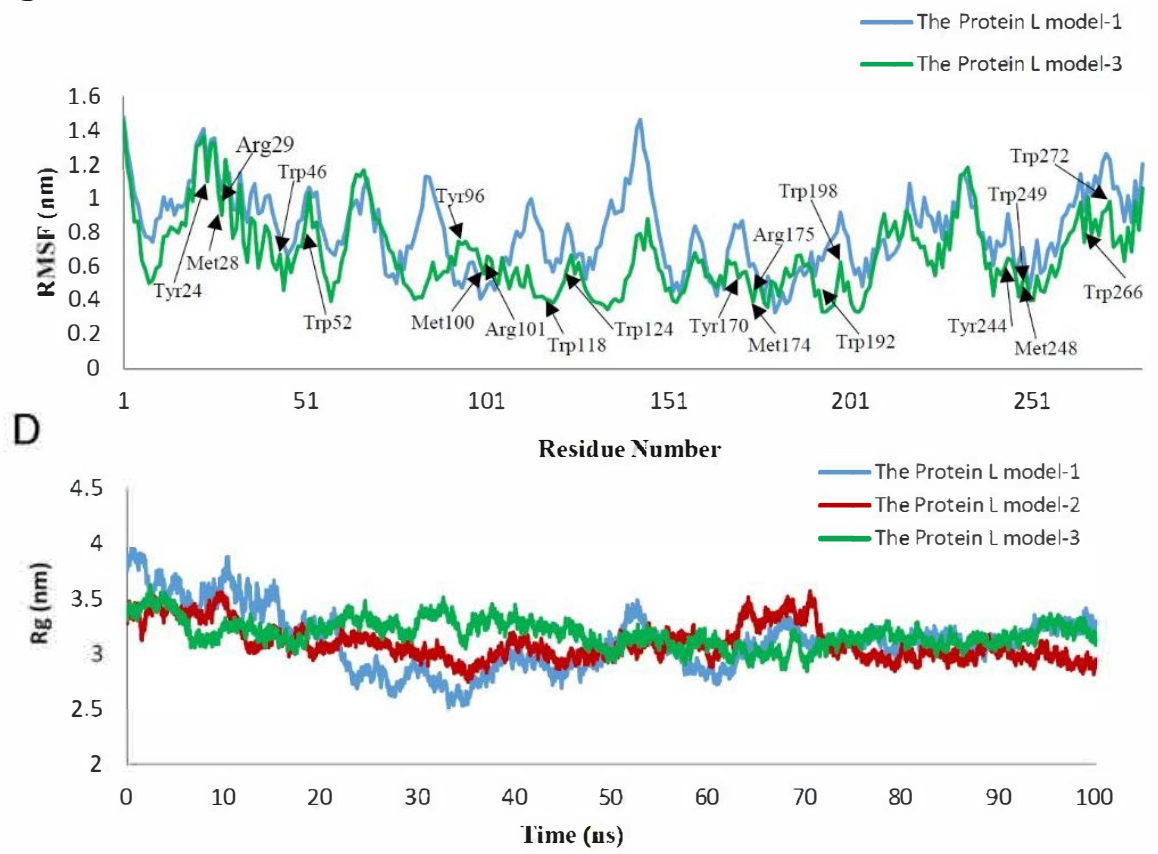

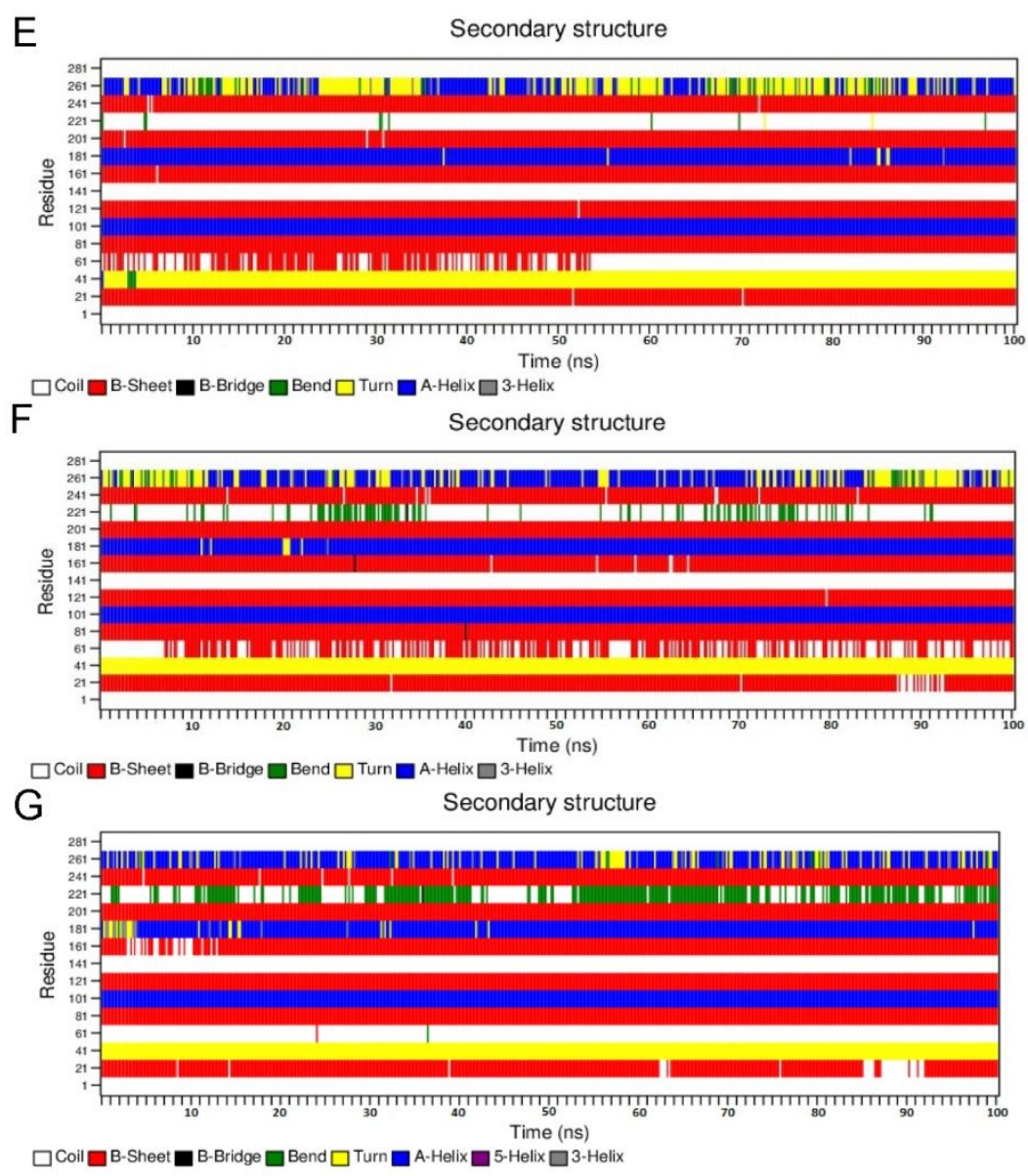

Figure S4- Molecular dynamics simulation of the engineered Proteins L including M1, M2 and M3 for 100ns. (A) The RMSD plot, (B,C) The RMSF plot, mutations in the first and second binding sites of B domains were displayed in plots, (D) The radius of gyration plot, $(\mathrm{E}, \mathrm{F}, \mathrm{G})$ The secondary structure using DSSP were indicated. The M1 (blue), the M2 (red) and the M3 (green) showed the engineered Proteins L during MD simulation. 


\section{A}
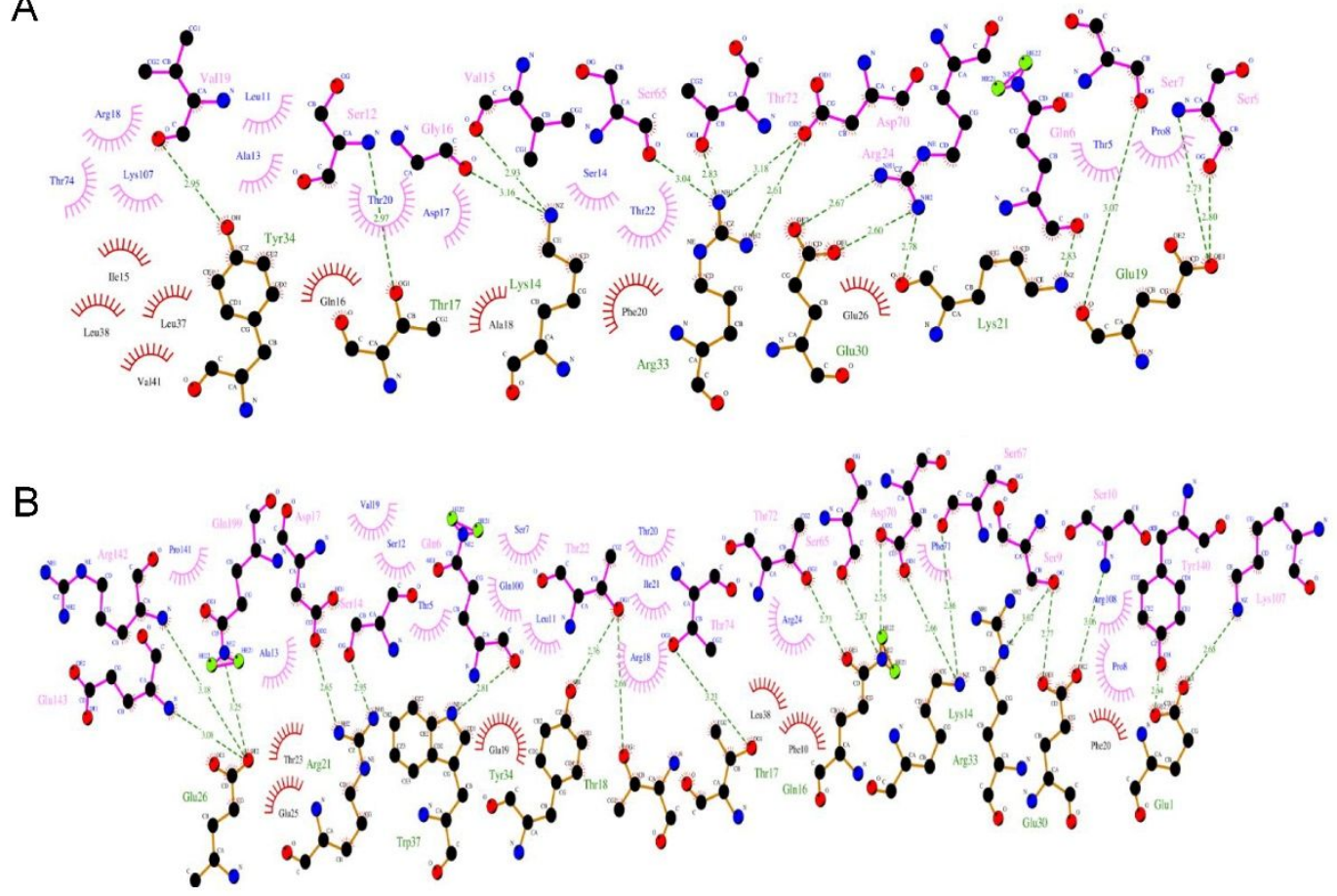

C
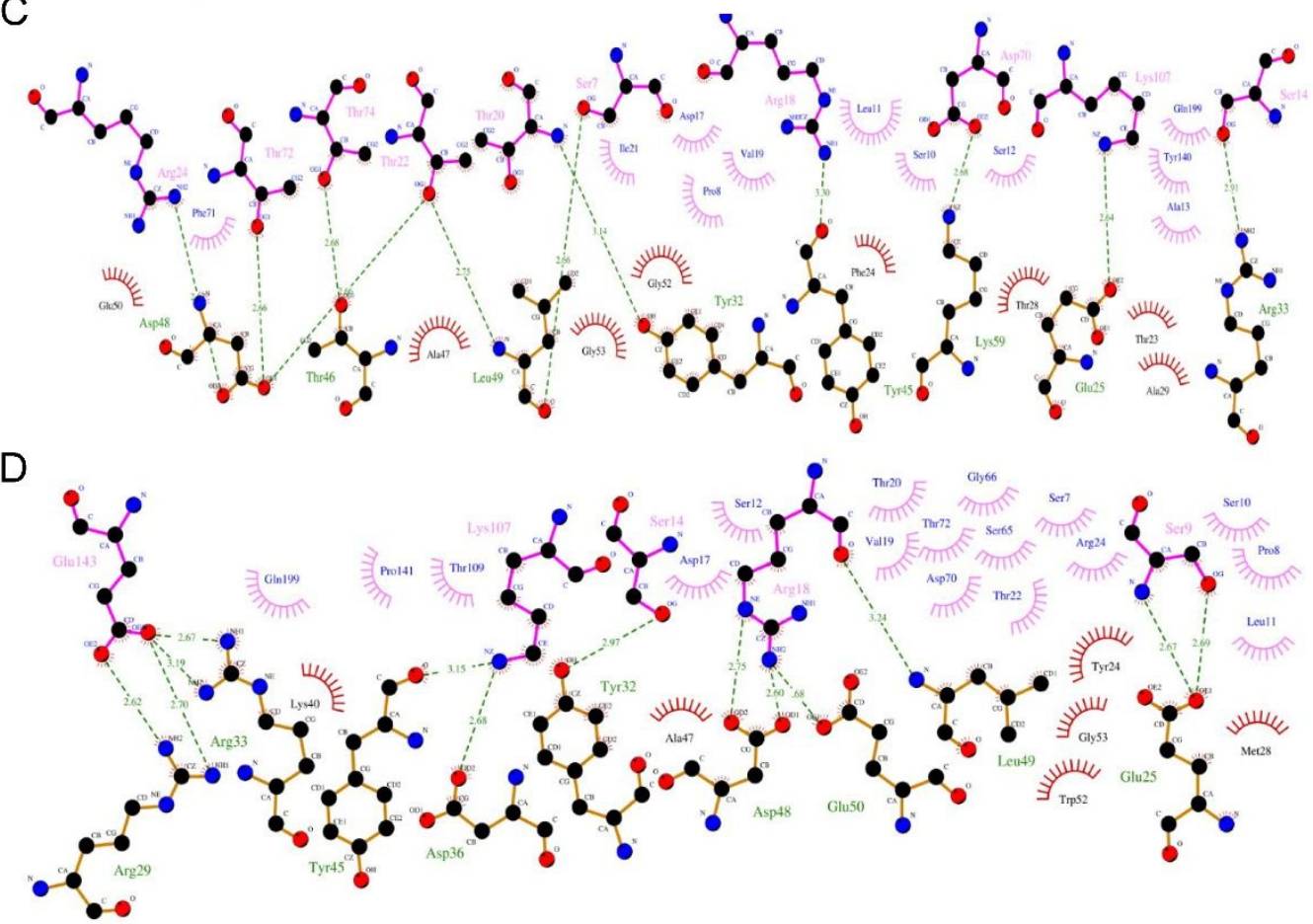

Figure S5- LigPlot analysis to determine the molecular interactions between the engineered Proteins $\mathrm{L}$ and Fab fragment using LigPlot. Interactions of the M1-Fab fragment (A) and the M2-Fab fragment (B) in the first binding site and interactions of the M1Fab fragment (C) and the M3-Fab fragment (D) in the second binding site were displayed using LigPlot. Residues of the engineered Proteins L (red), Fab fragment (pink) and hydrogen bonds (green bonds) were illustrated. 


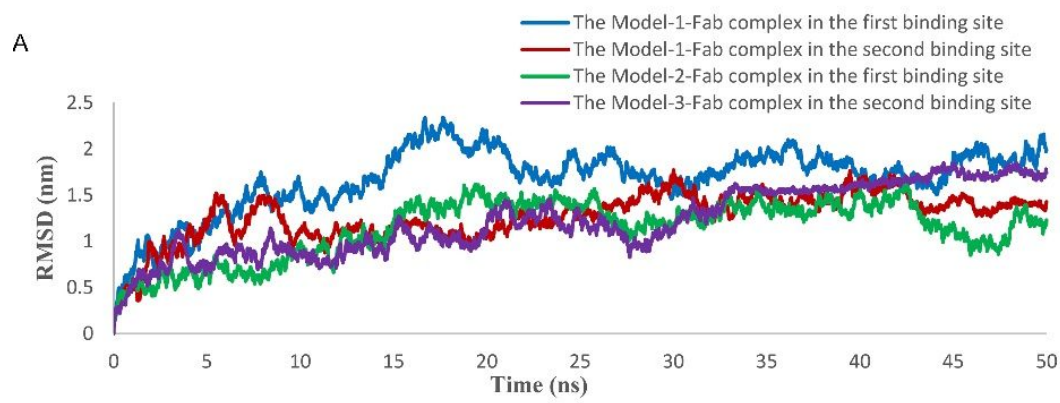

$B$

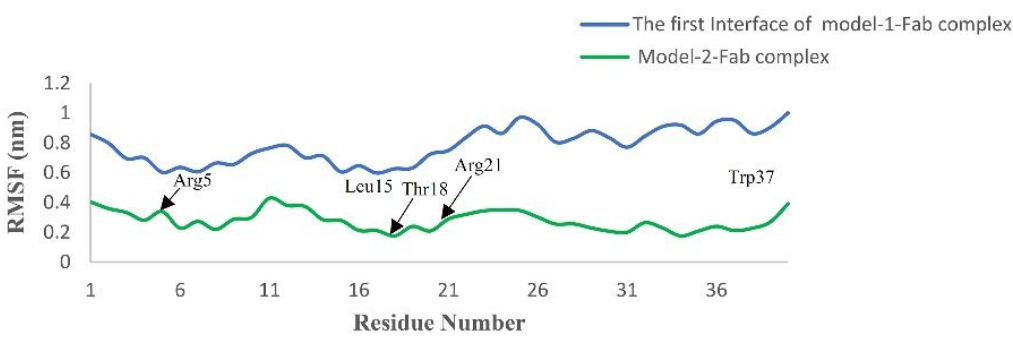

C

The second Interface of model-1-Fab complex - Model-3-Fab complex

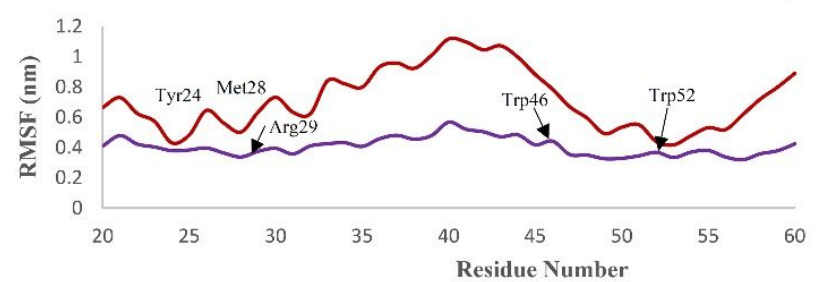

D

-The Model-1-Fab complex in the first binding site The Model-1-Fab complex in the second binding site The Model-2-Fab complex in the first binding site

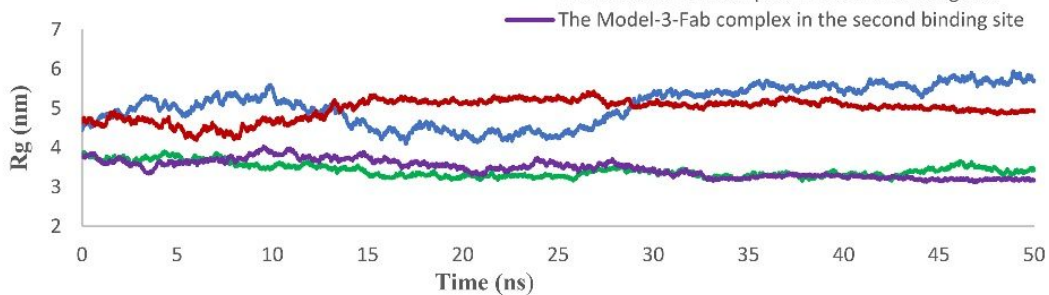

$E$

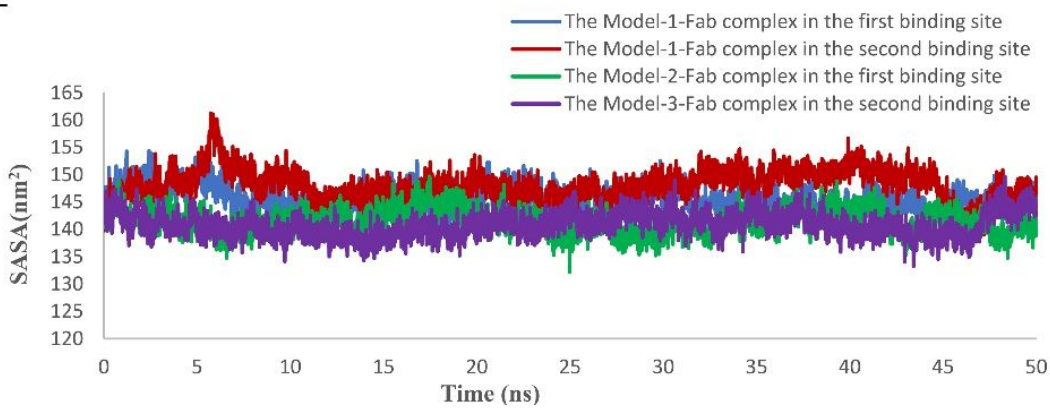

Figure S6- Molecular dynamics simulation of the engineered Proteins L -Fab complexes for 50ns. (A) The RMSD plot, (B, C) The RMSF plot, (B) mutations of Arg5, Leu15, Thr18, Arg21 and Trp37 in the binding site of M2 ( residues 1-40) and (C) mutations of Tyr24, Met28, Arg29, Trp46, Trp52 in the binding site of M3 ( residues 20-60) were presented in plots, (D) The radius of gyration plot, (E ) SASA plot were illustrated. The M1- Fab complex in the first binding site (blue), the M1- Fab complex in the 
second binding site (red), the M2- Fab complex in the first binding site (green), the M3- Fab complex in the second binding site (purple) has represented complexes during MD simulation.
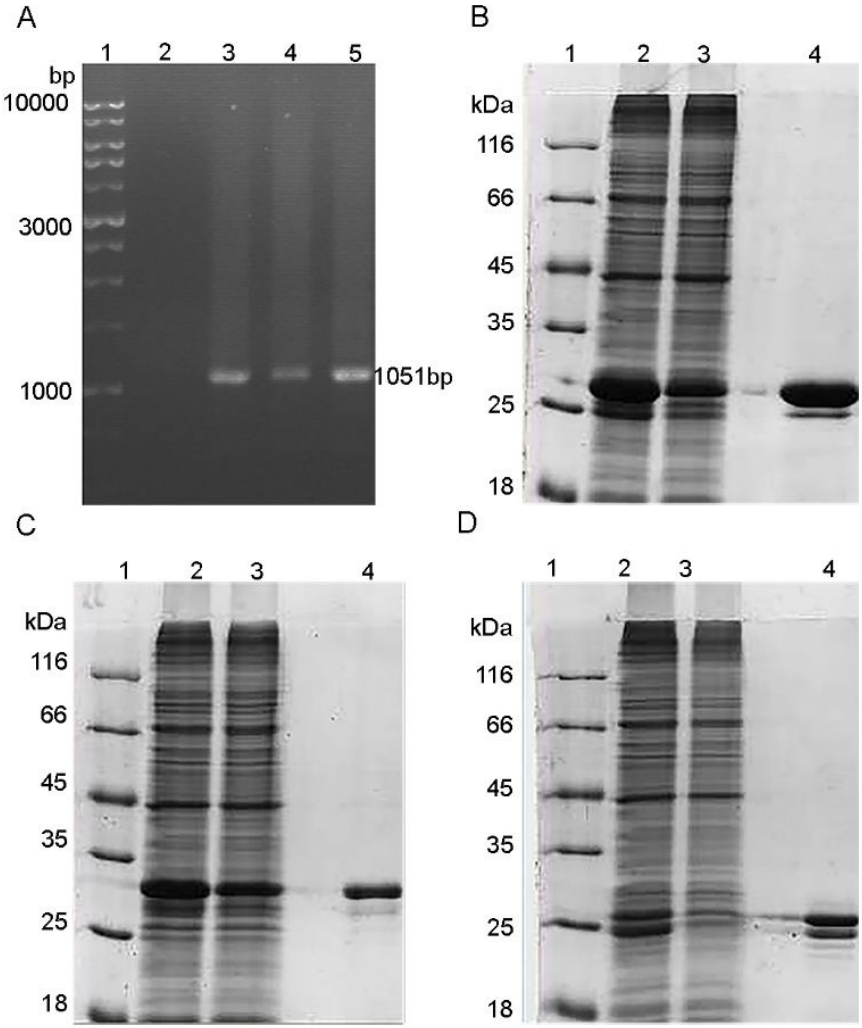

D

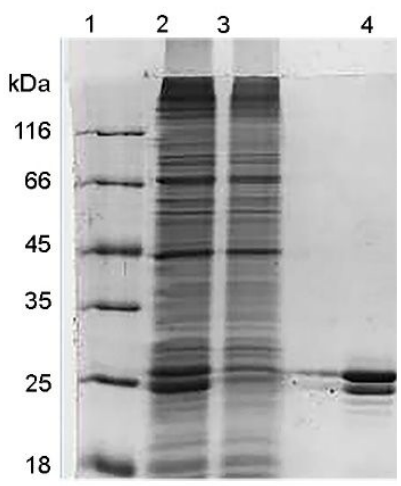

$\mathrm{E}$

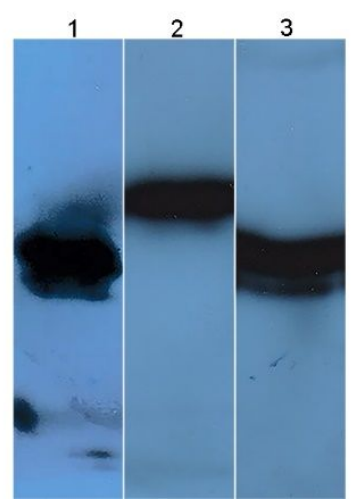

Figure S7. (A) Screening of positive clones by colony PCR. Lane 1: $1 \mathrm{~kb}$ DNA ladder, Lane 2: negative control, lane 3: M1 coding gene clone, lane 4: M2 coding gene clone, lane 5: M3 coding gene clone. (B, C, D) SDS-PAGE analysis of the EPLs purification using IgG-Sepharose resin after $4 \mathrm{~h}$ of induction with $0.1 \mathrm{mM} \mathrm{IPTG}$ at $37^{\circ} \mathrm{C}$. (B) 1: Molecular weight marker, 2: Lysate of M1, 3: Flow through of M1, 4: Elution M1. (C) 1: Molecular weight marker, 2: Lysate of M2, 3: Flow through of M2, 4: Elution M2. (D) 1: Molecular weight marker, 2: Lysate of M3, 3: Flow through of M3, 4: Elution M3. (E) Western blot analysis of purified EPLs using Ranibizumab as a primary antibody and anti-kappa HRP conjugate as a secondary antibody. 1: M1, 2: M2, and 3: M3. 


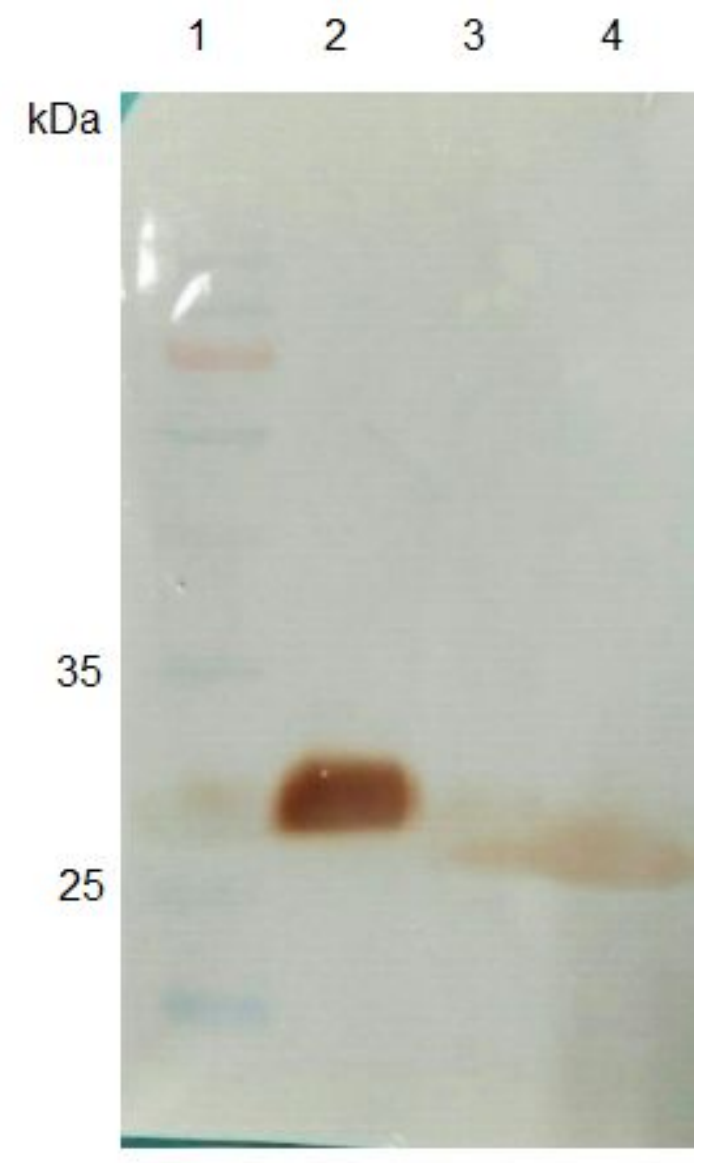

Figure S8. Western blot analysis of the EPLs in cell lysate using Ranibizumab as a primary Ab and anti-kappa HRP conjugate as a secondary Ab was shown. Lane 1: Molecular weight marker, lane 2: M1, lane 3: M2, and lane 4: M3.

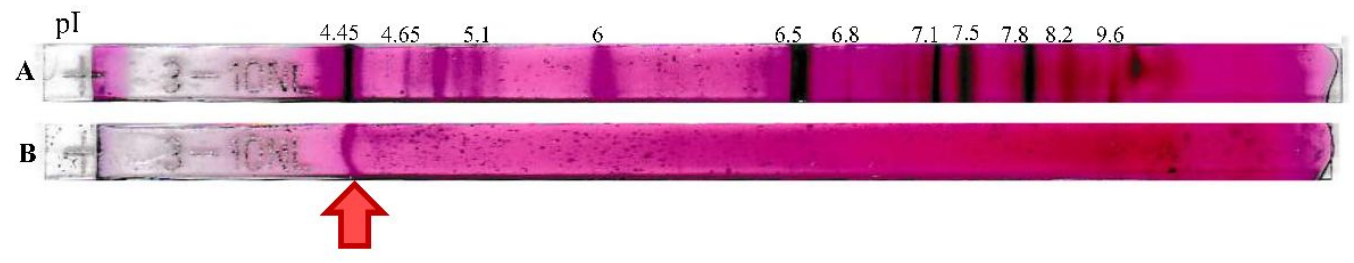

Figure S9. Isoelectric focusing electrophoresis analysis of the purified EPL M1 was demonstrated. Marker strip with gradient pI (A) and sample strip showed just one pI of 4.45 (B). 


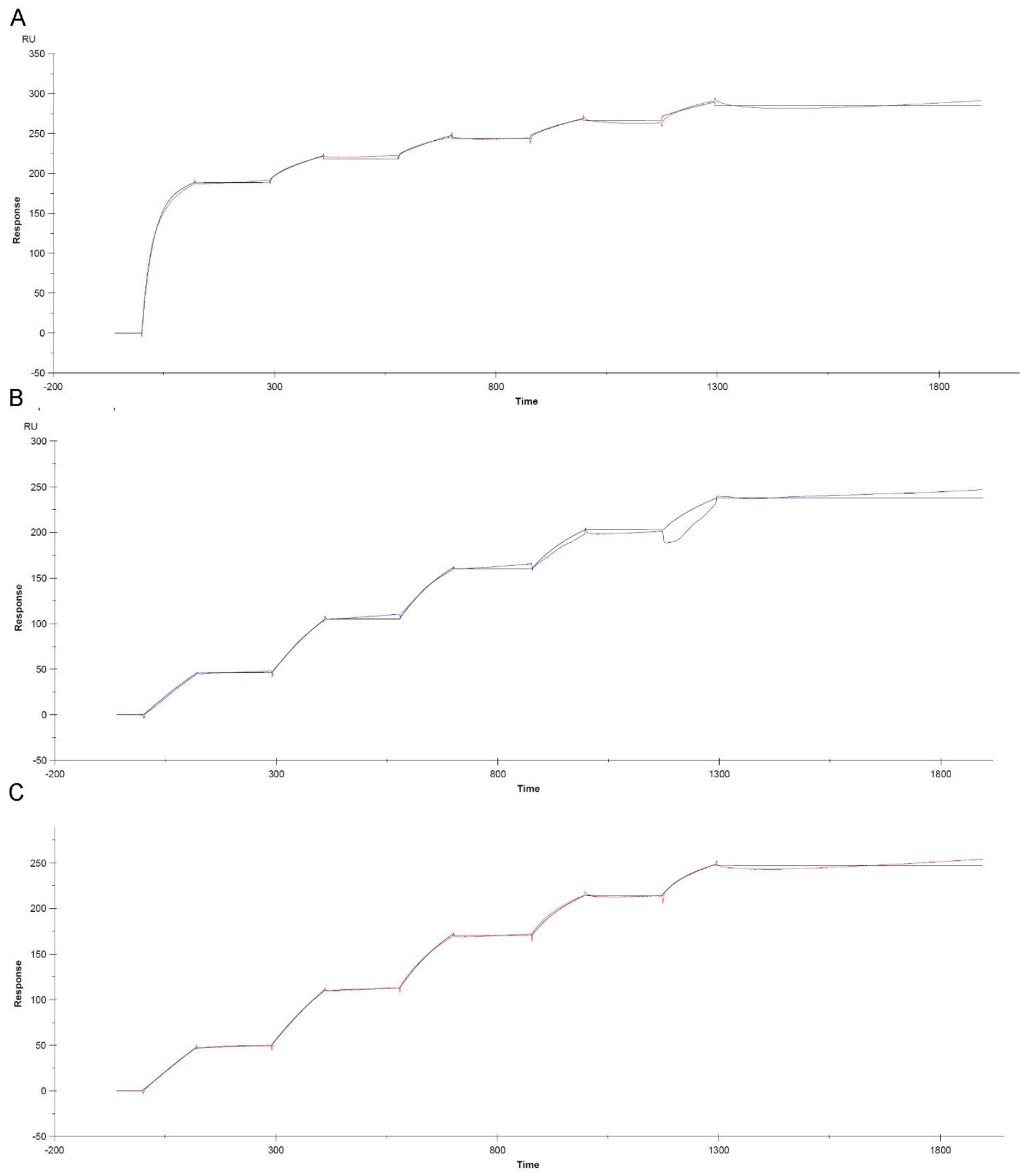

Figure S10. The SPR analysis to measure the binding affinities of the engineered Proteins L toward Fab fragment using Biacore X100 (GE healthcare, Sweden). The sensorgrams of M1 (A), M2 (B) and M3 (C) at the concentrations of $265 \mathrm{nM}, 132.5 \mathrm{nM}, 66.2$ $\mathrm{nM}, 33.1 \mathrm{nM}$ and $16.5 \mathrm{nM}$ have been demonstrated. 


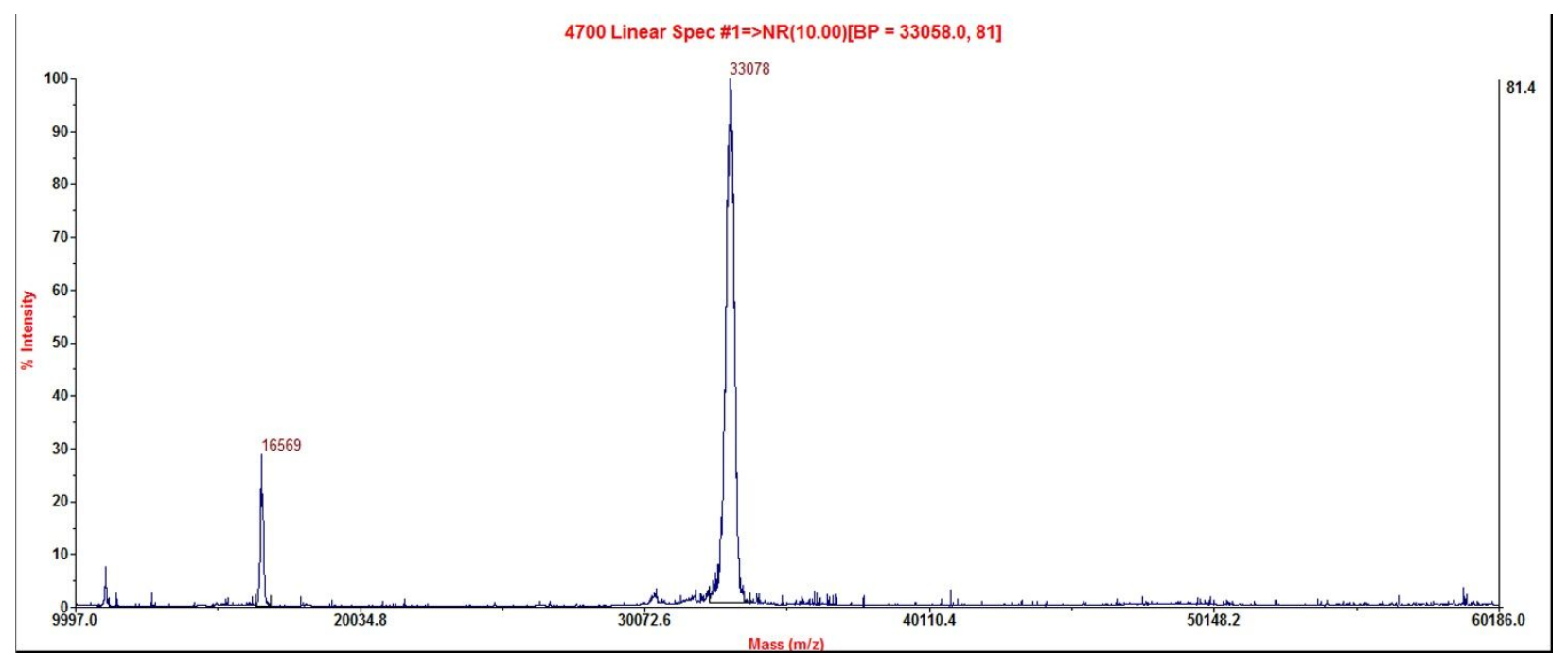

Figure S11. Mass spectrometry analysis of EPL M3 using MALDI TOF/TOF method.

\section{REFERENCES}

(1) Wallace, A. C.; Laskowski, R. A.; Thornton, J. M. Protein Eng 1995, 8, 127-134.

(2) Liu, Q.; Chen, P.; Wang, B.; Zhang, J.; Li, J. BMC Syst Biol 2018, 12, 132.

(3) Graille, M.; Stura, E. A.; Housden, N. G.; Beckingham, J. A.; Bottomley, S. P.; Beale, D.;

Taussig, M. J.; Sutton, B. J.; Gore, M. G.; Charbonnier, J. B. Structure 2001, 9, 679-687.

(4) Housden, N. G.; Harrison, S.; Housden, H. R.; Thomas, K. A.; Beckingham, J. A.; Roberts, S. E.; Bottomley, S. P.; Graille, M.; Stura, E.; Gore, M. G. J Biol Chem 2004, 279, 9370-9378.

(5) Kim, D. E.; Chivian, D.; Baker, D. Nucleic Acids Res 2004, 32, W526-531.

(6) Kruger, D. M.; Gohlke, H. Nucleic Acids Res 2010, 38, W480-486.

(7) Sukhwal, A.; Sowdhamini, R. Mol Biosyst 2013, 9, 1652-1661.

(8) Zhu, X.; Mitchell, J. C. Proteins 2011, 79, 2671-2683.

(9) Deng, L.; Zhang, Q. C.; Chen, Z.; Meng, Y.; Guan, J.; Zhou, S. Nucleic Acids Res 2014, 42, W290-295.

(10) Gainza, P.; Roberts, K. E.; Georgiev, I.; Lilien, R. H.; Keedy, D. A.; Chen, C. Y.; Reza, F.; Anderson, A. C.; Richardson, D. C.; Richardson, J. S.; Donald, B. R. Methods Enzymol 2013, 523, 87-107.

(11) Kozakov, D.; Hall, D. R.; Xia, B.; Porter, K. A.; Padhorny, D.; Yueh, C.; Beglov, D.; Vajda, S. Nat Protoc 2017, 12, 255-278. 
(12) van Zundert, G. C. P.; Rodrigues, J.; Trellet, M.; Schmitz, C.; Kastritis, P. L.; Karaca, E.; Melquiond, A. S. J.; van Dijk, M.; de Vries, S. J.; Bonvin, A. J Mol Biol 2016, 428, 720-725. (13) Xue, L. C.; Rodrigues, J. P.; Kastritis, P. L.; Bonvin, A. M.; Vangone, A. Bioinformatics 2016, 32, 3676-3678.

(14) Aliev, A. E.; Kulke, M.; Khaneja, H. S.; Chudasama, V.; Sheppard, T. D.; Lanigan, R. M. Proteins 2014, 82, 195-215.

(15) Bagherzadeh, K.; Shirgahi Talari, F.; Sharifi, A.; Ganjali, M. R.; Saboury, A. A.; Amanlou, M. J Biomol Struct Dyn 2015, 33, 487-501.

(16) Mostafavi, S. M.; Bagherzadeh, K.; Amanlou, M. Medbiotech Journal 2017, 1, 1-8.

(17) Murphy, J. P.; Duggleby, C. J.; Atkinson, M. A.; Trowern, A. R.; Atkinson, T.; Goward, C. R. Mol Microbiol 1994, 12, 911-920.

(18) Vostakolaei, M. A.; Molavi, O.; Hejazi, M. S.; Kordi, S.; Rahmati, S.; Barzegari, A.; Abdolalizadeh, J. J Cell Biochem 2019, 120, 14711-14724.

(19) Webb, B.; Sali, A. Methods Mol Biol 2021, 2199, 239-255.

(20) Dhal, A. K.; Pani, A.; Mahapatra, R. K.; Yun, S. I. Immunobiology 2019, 224, 747-757.

(21) Wiederstein, M.; Sippl, M. J. Nucleic Acids Res 2007, 35, W407-410.

(22) Eisenberg, D.; Luthy, R.; Bowie, J. U. Methods Enzymol 1997, 277, 396-404.

(23) Humphrey, W.; Dalke, A.; Schulten, K. J Mol Graph 1996, 14, 33-38, 27-38.

(24) Schrodinger, L. Version 2010, 1, 0.

(25) Puigbo, P.; Guzman, E.; Romeu, A.; Garcia-Vallve, S. Nucleic Acids Res 2007, 35, W126131.

(26) Song, H. N.; Kim, D. H.; Park, S. G.; Lee, M. K.; Paek, S. H.; Woo, E. J. Biosci Biotechnol Biochem 2015, 79, 718-724.

(27) Åkerström, B.; Björck, L. Journal of Biological Chemistry 1989, 264, 19740-19746. 